\title{
Comparative Evaluation of Glibenclamide and Insulin on the Pups' Liver Cytoarchitectonic Properties and Some Dams' Parameters in Pregnant Streptozotocin-Induced Diabetic Rats
}

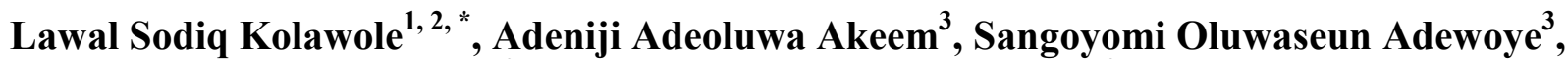 \\ Adeyemo Rasheed Omotayo ${ }^{2}$, Buhari Muhammad Olanrewaju ${ }^{2}$, Sulaiman Sheu Oluwadare ${ }^{4}$, \\ Osinubi Abraham Adewale ${ }^{3}$ \\ ${ }^{1}$ Department of Anatomy, St. Francis University College of Health Sciences and Allied Sciences, Ifakara, Tanzania \\ ${ }^{2}$ Department of Anatomy, Western Campus, Kampala International University, Ishaka-Bushenyi, Uganda \\ ${ }^{3}$ Department of Anatomy, College of Medicine, University of Lagos, Idi-Araba, Lagos, Nigeria \\ ${ }^{4}$ Department of Physiology, Faculty of Medicine, Kampala International University in Tanzania, Dar es Salaam, Tanzania
}

Email address:

slawal@sfuchas.ac.tz (L. S. Kolawole)

${ }^{*}$ Corresponding author

To cite this article:

Lawal Sodiq Kolawole, Adeniji Adeoluwa Akeem, Sangoyomi Oluwaseun Adewoye, Adeyemo Rasheed Omotayo, Buhari Muhammad Olanrewaju, Sulaiman Sheu Oluwadare, Osinubi Abraham Adewale. Comparative Evaluation of Glibenclamide and Insulin on the Pups' Liver Cytoarchitectonic Properties and Some Dams' Parameters in Pregnant Streptozotocin-Induced Diabetic Rats. American Journal of Psychiatry and Neuroscience. Vol. 6, No. 1, 2018, pp. 9-14. doi: 10.11648/j.ajpn.20180601.12

Received: November 21, 2017; Accepted: December 6, 2017; Published: January 11, 2018

\begin{abstract}
Despite the significant achievements in the treatment modalities and preventive measures, the prevalence of gestational diabetes in Africa has continued to rise exponentially in the last few decades. There is growing concern on the use of oral hypoglycemic agents (OHAs) during pregnancy, due to the potential of the agents in causing adverse effect (s) on the developing fetus and its effectiveness in managing the gestational diabetes mellitus. The objective of this study was to investigate the action of glibenclamide compared with insulin on pups' liver cytoarchitectonic property and oxidative stress markers, and on maternal glucose level and sexual hormonal profile. Twenty pregnant female Sprague-Dawley rats (120-160 g) divided into 4 groups A, B, C and D ( $\mathrm{n}=5$ per group) were used for the study. Rats in group A (control) were given $0.5 \mathrm{ml}$ distilled water daily while the rats in groups B, C, and D were rendered diabetic by administration of intraperitoneal low-dose streptozotocin (STZ) and subsequently treated with $0.5 \mathrm{mls}$ of distilled water, glibenclamide $(0.29 \mathrm{mg} / \mathrm{kg}$ body weight $)$ and insulin (1 UI daily) respectively. Blood glucose levels were monitored and recorded throughout the experiment. The rats were sacrificed on the $19^{\text {th }}$ day of gestational period. The pups' liver and maternal blood sample were collected for analysis. The glibenclamide and insulin groups showed significant $(p \leq 0.05)$ decreased in blood glucose with an increased maternal body weight when compared to the diabetic group. The activities of GSH, SOD and CAT were significantly increased $(p \leq 0.05)$ in the glibenclamide and insulin treated groups compared to the diabetic group. Also, MDA significantly reduced in the glibenclamide and insulin treated groups (C \& D) when compared to the diabetic untreated group (B) with the greater reduction observed for insulin. There was an improvement in the hormonal profiles of glibenclamide and insulin treated groups compared with the diabetic group. Histologically, glibenclamide and insulin showed an improvement in the arrangement of cytoarchitectonic property of pups' liver with mild steatosis compared with diabetic group. Based on our observations in this study, it was concluded that glibenclamide is as effective as insulin with no or little negative effect and could be an optional drug to be used in the treatment of gestational diabetes mellitus in place of insulin.
\end{abstract}

Keywords: Cytoarchitectonic, Gestational Maternal Diabetes, Glibenclamide, Pups, Dams 


\section{Introduction}

Diabetes mellitus is a chronic metabolic disease characterized by hyperglycaemia and glycosuria due to absolute or relative lack of insulin [1]. The mainstay in the treatment of gestational diabetes mellitus is insulin [2], but the insulin can lead to maternal hypoglycaemia which can influence the fetal defects depending on the dosage and period of exposure [3]. Gestational Diabetes Mellitus (GDM) and impaired glucose tolerance (IGT) are the bases for the use of oral hypoglycemic agents (OHAs) in pregnancy [4]. There is growing concern about the use of OHAs due to the potentials of these agents to cause adverse effects on the developing fetus with the assumption that significant transfer occurs across the placenta [5].

The prevalence of GDM is on the increase and is projected by the World Health Organization (WHO) to rise to 366 Million worldwide by the year 2030 [6]. Nigeria, in recent decades, has been faced with many topical issues of which diabetes mellitus is one of them [7].

The onset of diabetes is accompanied by the development of major biochemical and functional abnormalities in the liver, including alterations in carbohydrate, lipid, protein metabolism and changes in antioxidant status [8]. The prevalence of the hepatobiliary disease increased in patients with type 1 or type 2 diabetes mellitus [9].

\section{Material and Method}

\subsection{Animals}

Twenty (20) Virgin female and 5 male Sprague-Dawley rats weighing between 120-160g were procured from Animal Laboratory Centre of College of Medicine, University of Lagos. The animals were housed in wire-mesh cages in the animal room of the Department of Anatomy of the University of Lagos. The animals were weighed and randomly divided after three weeks of acclimatization. It must be emphasized here that the Animal Research Laboratory was maintained at a temperature of $26-28^{\circ} \mathrm{C}$ and $12: 12$ light: dark cycle.

\subsection{Determination of the Estrous Cycle}

The phases of estrous cycle were determined by daily examination of vaginal smear as described $[10,11]$. Vaginal smear was taken once each day between $7 \mathrm{am}$ and $10 \mathrm{am}$. The sample of smear containing cells was placed on an untreated glass microscopic slide and viewed while still wet under a light microscope at 100x magnification. The phases of the estrous cycle were determined and recorded for 3 weeks. Animals with regular estrous cycle were used for the experiment. All rats were handled in accordance with the standard guide for the care and use of animals in the laboratory.

\subsection{Induction of Diabetes}

Diabetes mellitus was induced in overnight fasted rats by a double intra-peritoneal injection of streptozotocin (45 and 35 $\mathrm{mg} / \mathrm{kg} \mathrm{b}$. w) in $0.1 \mathrm{M}$ sodium citrate buffer ( $\mathrm{pH} 4.5)$. The agematched control rats respectively received an equivalent amount of citrate buffer $[12,13]$. Food and water intake were closely monitored daily after streptozotocin (STZ) administration. The development of hyperglycaemia in rats was confirmed by fasting blood glucose (FBG) level measurement, via the tail vein, 48 hrs after STZ administration with a portable glucometer (Accu-chek, Roche, Germany). The animals with FBG level $\geq 300 \mathrm{mg} / \mathrm{dl}$ were considered diabetic [12].

\subsection{Dosage of Test Agents and Treatment}

The animals were randomly divided into 4 groups (A-D). Each group comprised five rats. Distilled water, insulin, glibenclamide were administered once daily.

Group A: Non-diabetic+ distilled water $(0.5 \mathrm{ml})$

Group B: Diabetic + distilled water $(0.5 \mathrm{ml})$

Group C: Diabetic + glibenclamide $(0.26 \mathrm{mg} / \mathrm{kg}$ b.w $)$

Group D: Diabetic + insulin (1 IU daily)

\subsection{Measurement of Maternal Body Weight}

The body weights of all the animals from each group were measured and recorded daily throughout the experiment using sensitive weighing balance.

\subsection{Maternal Blood Sample Collection and Pups' Liver Tissue Preparation}

Animals were sacrificed on the $19^{\text {th }}$ day of the 21 day gestational period through cervical dislocation. Blood samples were obtained through the apex of the heart. Morphological appearance of the pups was observed and their liver tissues were harvested. Some liver tissue blocks were processed for haematoxylin and eosins (H\&E) histological observation while other blocks were homogenized and used for analysis of oxidative stress markers.

\subsection{Statistical Analysis}

The results of the blood glucose level before and after treatment were expressed as Mean \pm SEM. The data analysis was done using one-way ANOVA followed by Tukey's multiple post hoc tests using Graph Pad Prism 5 (Graph Pad Software Inc, CA. USA). Significance of comparisons was taken at $p \leq 0.05$.

\section{Results}

\subsection{Maternal Blood Glucose Level}

Table 1: There was a statistically significant decrease in blood glucose level across the treated groups (C-D) compared to group A (control) and group B (diabetes without drug). The experimentally induced diabetic rats administered with glibenclamide $0.29 \mathrm{mg} / \mathrm{Kg} /$ day showed a reduction in 
blood glucose level throughout the experimental period. However, there were significant reductions in glibenclamide $(382.71 \pm 66.895$ to $121.50 \pm 3.782)$ and insulin
$(470.00 \pm 45.354$ to $123.40 \pm 8.961)$ treated groups on the $18^{\text {th }}$ day when compared with the diabetic group.

Table 1. Summary of the mean blood glucose level $(\mathrm{mg} / \mathrm{dl})$ of animals across all groups.

\begin{tabular}{|c|c|c|c|c|c|}
\hline Group/Days & DAY 2 & DAY 6 & DAY 10 & DAY 14 & DAY 18 \\
\hline Group A: Control & $79.86 \pm 6.543$ & $78.86 \pm 8.533$ & $82.14 \pm 9.477$ & $80.43 \pm 6.188$ & $80.14 \pm 7.221$ \\
\hline Group B: Diabetic & $469.57 \pm 56.471$ & $478.83 \pm 51.219$ & $468.00 \pm 71.165$ & $470.40 \pm 68.966$ & $467.20 \pm 65.308$ \\
\hline Group C: Glibenclamide & $382.71 \pm 66.895^{\mathrm{bd}}$ & $310.17 \pm 59.550^{\text {bd }}$ & $237.50 \pm 45.768^{\mathrm{bd}}$ & $176.00 \pm 20.659^{\text {bd }}$ & $121.50 \pm 3.782^{\mathrm{b}}$ \\
\hline
\end{tabular}

Values are expressed as mean \pm Standard Error of Mean (SEM).

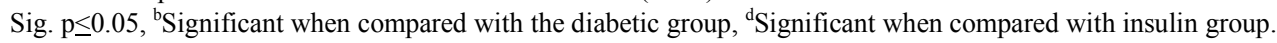

\subsection{Maternal Body Weight Difference}

Table 2: There were no statistically significant differences in the mean weight of the treated groups (C \& D) but diabetic group without treatment $(\mathrm{B})$ was significantly decreased $(p \leq 0.05)$ in weight. Glibenclamide and insulin treated groups $(\mathrm{C} \& \mathrm{D})$ showed a significant increase in weight gain when compared with the diabetic group (B). The weight gain was more in the insulin-treated group.

Table 2. Summary of the weight difference ( $g$ ) of animals across all groups.

\begin{tabular}{lllll}
\hline Group/days & DAY 2 & DAY 6 & DAY 10 & DAY 14 \\
\hline Group A: Control & $146.57 \pm 9.998$ & $149.50 \pm 10.310$ & $156.00 \pm 10.050$ & $158.40 \pm 9.659$ \\
Group B: Diabetic & $151.14 \pm 2.854$ & $145.50 \pm 2.881$ & $138.60 \pm 3.435$ & $159.20 \pm 10.085^{\text {b }}$ \\
Group C: Glibenclamide & $155.29 \pm 3.904$ & $153.50 \pm 4.637$ & $153.33 \pm 4.761$ & $136.00 \pm 3.536$ \\
Group D: Insulin & $144.14 \pm 3.934$ & $149.71 \pm 3.352$ & $168.43 \pm 3.924$ & $136.00 \pm 353$ \\
\hline
\end{tabular}

Sig. $\mathrm{p} \leq 0.05$, ${ }^{\mathrm{b}}$ Significant when compared with the diabetic group.

\subsection{Oxidative Stress Markers}

Table 3: The activities of GSH, SOD and CAT were significantly decreased $(p \leq 0.05)$ in diabetic group compared to the glibenclamide and insulin groups. Also in this study, there was a statistically significant increase of CAT (678.45 \pm 52.71 ) recorded in insulin group when compared with glibenclamide group (482.80 \pm 160.80$)$. MDA significantly increased in the diabetes group (B) when compared to the control group (A). However, the increased MDA was significantly reduced in the glibenclamide and insulin treated groups $(\mathrm{C} \& \mathrm{D})$ when compared to the diabetic untreated group (B) with the greater reduction observed for insulin.

Table 3. Summary of the mean pups' liver oxidative stress markers of animals across all groups.

\begin{tabular}{lllll}
\hline Group & GSH U/mg & SOD U/mg & CAT U/mg & MDA U/mg \\
\hline Group A: Control & $8.71 \pm 1.51^{\text {bd }}$ & $94.23 \pm 3.74$ & $816.46 \pm 42.12^{\text {bcd }}$ & $0.65 \pm 0.32$ \\
Group B: Diabetic & $0.72 \pm 0.58$ & $45.13 \pm 7.03^{\text {acd }}$ & $428.42 \pm 91.89^{\text {acd }}$ & $4.95 \pm 0.52^{\text {acd }}$ \\
Group C: Glibenclamde & $6.14 \pm 5.13^{\text {bd }}$ & $87.40 \pm 7.72^{\text {bd }}$ & $482.80 \pm 160.80^{\mathrm{b}}$ & $2.52 \pm 1.74^{\text {bd }}$ \\
Group D: Insulin & $2.25 \pm 0.62^{\mathrm{b}}$ & $77.20 \pm 9.58^{\mathrm{b}}$ & $678.45 \pm 52.71^{\mathrm{bc}}$ & $1.67 \pm 0.25^{\mathrm{b}}$ \\
\hline
\end{tabular}

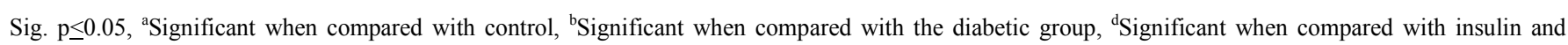

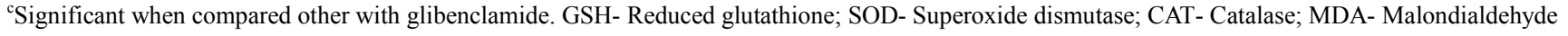

\subsection{Hormonal Profile}

Table 4: The FSH, PRL, PROG, and E2 were significantly increased $(p \leq 0.05)$ in glibenclamide and insulin groups when compared with the diabetic group. In insulin group, the PRL was significantly reduced $(0.42 \pm 0.15)$ when compared with glibenclamide $(1.00 \pm 0.14)$ and diabetic groups $(0.46 \pm 0.11)$.

Table 4. Summary of the descriptive statistics of the mean hormonal profiles of animals across all groups.

\begin{tabular}{lllll}
\hline Group & LH & FSH & PRL & PROG \\
\hline GroupA: Control & $0.14 \pm 0.05$ & $0.20 \pm 0.07^{\mathrm{b}}$ & $1.18 \pm 0.08^{\mathrm{b}}$ & $16.90 \pm 0.44^{\mathrm{b}}$ \\
Group B: Diabetic & $0.22 \pm 0.13^{\mathrm{a}}$ & $0.14 \pm 0.05^{\mathrm{b}}$ & $0.46 \pm 0.11^{\mathrm{c}}$ & $8.60 \pm 1.15^{\mathrm{acd}}$ \\
GroupC: Glibenclamide & $0.42 \pm 0.16^{\mathrm{c}}$ & $1.00 \pm 0.16^{\mathrm{c}}$ & $1.00 \pm 0.14^{\mathrm{bd}}$ & $21.75 \pm 3.2^{\text {abd }}$ \\
Group D: Insulin & $0.56 \pm 0.09^{\mathrm{abc}}$ & $0.72 \pm 0.42^{\mathrm{b}}$ & $0.42 \pm 0.15$ & $19.47 \pm 0.11^{\mathrm{a}}$ \\
\hline
\end{tabular}

Note that: LH (Luteinizing Hormone), FSH (Follicle Stimulating Hormone), PRL (Prolactin), PROG (Progesterone), E2 (Estradiol).

Sig. $\mathrm{p} \leq 0.05$, ${ }^{\mathrm{a}}$ Significant when compared with control, ${ }^{\mathrm{b}}$ Significant when compared with diabetic, ${ }^{\mathrm{d}}$ Significant when compared with insulin. 


\subsection{Histology Parameter}

Figure 1-4: The results of the light microscopic study of the liver showed various degrees of dilation of intrahepatic vessels, mild and severe steatosis of the treated animals compared to the control group. Group A (control) showed the normal arrangement of hepatocytes and no steatosis was visible. In group B (diabetes without treatment), liver histology showed vascular congestion and zonal necrosis with severe steatosis. Group C and D showed well-arranged hepatocytes with micro-steatosis. In addition, there was the presence of vascular congestion in group D.

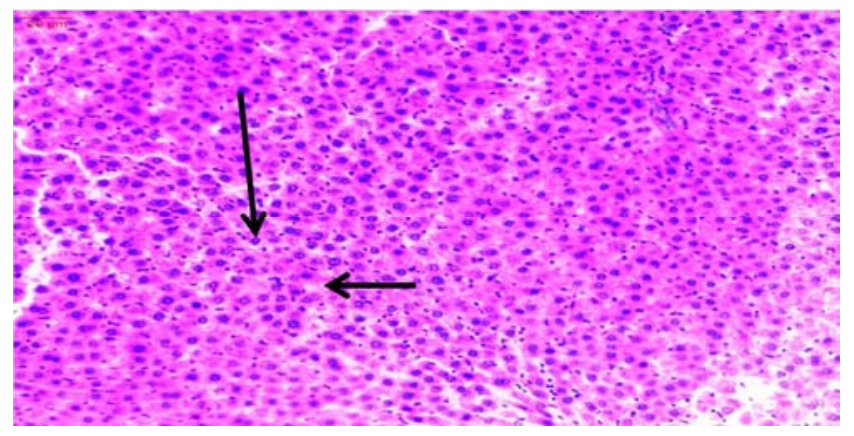

Figure 1. (Control): Photomicrograph of the pup's liver using $H \& E$ (x100), showing normal Hepatocytes and no fibrosis was visible (vertical arrow). Also, there was normal vacuolization (horizontal arrow).

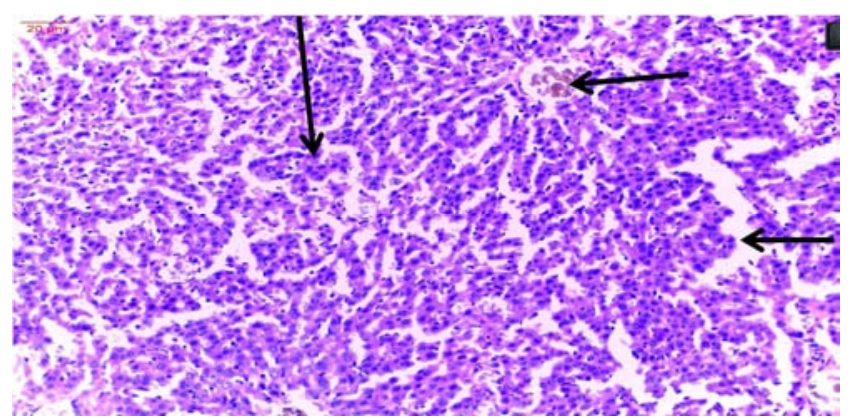

Figure 2. (Diabetes): Photomicrograph of the pup's liver using H\&E (x100), showing vacuolization of the Hepatocytes cytoplasm (vertical arrows), vascular congestion and zonal necrosis (horizontal arrow).

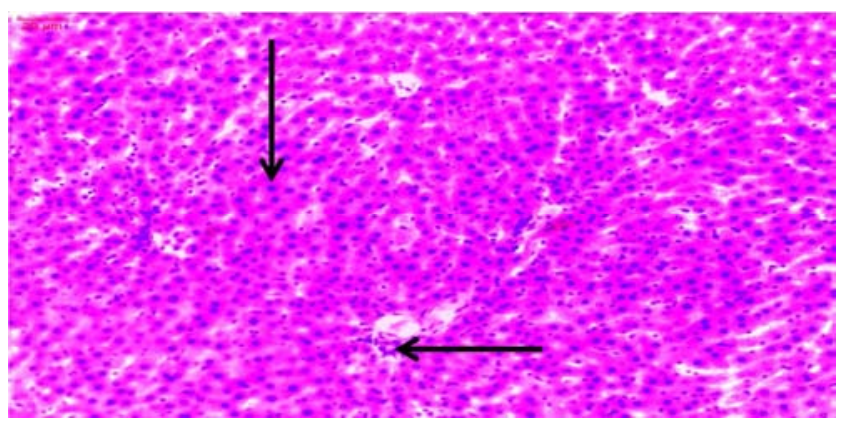

Figure 3. (Glibenclamide): Photomicrograph of the pup's liver using $H \& E$ (100), showing normal Hepatocytes (vertical arrow) and microsteatosis (horizontal arrow).

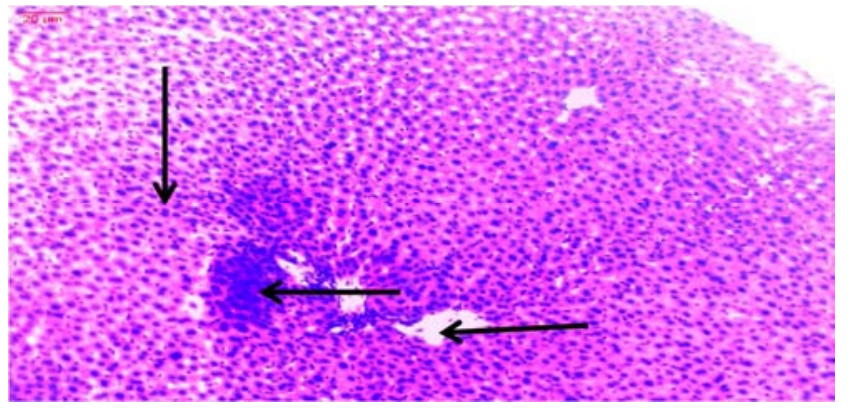

Figure 4. (Insulin): Photomicrograph of the pup's liver using $H \& E$ (x100), showing micro vacuolization of the Hepatocytes cytoplasm, micro-steatosis and vascular congestion (vertical and horizontal arrows).

\section{Discussion}

The investigation on the effectiveness and safety of glibenclamide has been scanty while the prevalence of overt diabetes in pregnancy and glucose intolerance in pregnancy (Gestational diabetes mellitus) has been risen [14]. Bharti reported that administration of oral anti-diabetic agent (OHA) instead of insulin appears to be tempting, as they prove to be effective but there is a paucity of data on the exposure of the foetus to their mother's OHAs during pregnancy as well as in infancy during breastfeeding [15]. Therefore, this research was designed to investigate the effectiveness and safety of glibenclamide compared to insulin in the treatment of gestational diabetes mellitus using STZ-induced diabetic pregnant rats.

The results obtained in this research work showed that glibenclamide indeed slowed progression of hyperglycaemia in STZ-induced diabetic pregnant rats. There was a statistically significant decrease in blood glucose level across the treated groups (C-D) compared to group A (control) and group B (diabetes without drug). The experimentally induced diabetic rats administered with glibenclamide $0.29 \mathrm{mg} / \mathrm{Kg} /$ day showed a reduction in blood glucose level throughout the experimental period with a significant reduction in both glibenclamide and insulin groups on the $18^{\text {th }}$ day when compared with the diabetic group.

There were no statistically significant differences in the means weight of the treated groups $(C \& D)$ but diabetic group without treatment was significantly decreased $(p \leq 0.05)$ in weight. Glibenclamide and insulin groups showed a significant increase in weight gain when compared with the diabetic group as supported by previous reports $[16,17]$.

The results of the light microscopic study of the liver showed various degrees of dilation of intrahepatic vessels, mild and severe steatosis of the treated animals compared to the control group. In group B (diabetes without treatment) liver histology showed severe steatotic hepatocytes and portal space. As reported by Ogunmodede, the role of oxidative stress in the pathogenesis and complications of diabetes mellitus is well recognized and long-term complications of diabetes include damage to blood vessels, which can affect various organs [18]. In the treated groups (C $\& \mathrm{D})$, there were micro (reduced) steatosis of hepatocytes 
and portal space compared to the diabetic untreated group. Insulin promotes the uptake of sugar by almost all of the body's cells including liver and fat cells. In this research, insulin improved glycaemic control with no deleterious effect on the cell but associated with weight gain as supported by other reports $[19,20]$. Administration of glibenclamide showed no statistically significant difference in weight and no deleterious effects on the liver hepatocytes. This effective glycaemic control of glibenclamide could have a positive impact in protecting the foetal's liver cells, as Coetzee reported that retrospective studies done in rats and rabbits at higher doses of glibenclamide revealed no evidence of impaired fertility and harm to the major organs [21].

Oxidative stress has lately been reported to be responsible, to a certain extent, for the $\beta$-cell dysfunction caused by glucose toxicity [22]. In this study, there was statistically significant association recorded in the level of oxidative stress markers in group $\mathrm{B}, \mathrm{C}$ and $\mathrm{D}$ compared with the control (group A) as shown in Table 3. There was a statistically significant decrease in the level of SOD $(p \leq 0.05)$ in group B (diabetic) when compared with the group A (control), group C (glibenclamide) and group D (Insulin). The role of oxidative stress in diabetes mellitus is well documented and the ability of glibenclamide to improve the level of SOD was also previously reported by Omotayo [23]. In contrary to this, Glibenclamide has been reported to have no significant effects on oxidative stress marker [24].

Glutathione is the most abundant intracellular antioxidant and its plays central role in the body defense mechanism [25]. GSH was significantly $(\mathrm{p} \leq 0.05)$ increased in glibenclamide and insulin when compared with the diabetic group. The increased level of the GSH may be as a result of glycaemic control activities of both the glibenclamide and insulin in the present study which is in accordance with the previous study [26].

Catalase (CAT) activities in the tissue were significantly $(p \leq 0.05)$ reduced in the diabetic group B compared with the group A (control), Group C (glibenclamide) and group D (insulin) rats. Insulin administration significantly $(p \leq 0.05)$ up-regulated CAT activity compared to the diabetic group and even glibenclamide group. MDA level was significantly higher in the diabetic group than the control, glibenclamide and insulin groups. The glibenclamide and insulin treated groups showed a significant reduction in MDA level towards the control level compared to the diabetic group but the reduction was more in the insulin group than the glibenclamide group. The increased CAT and reduced MDA in insulin treated group more than glibenclamide treated group might show that antioxidant property of insulin is higher than that of glibenclamide and this can be supported by the report of Omotayo et al. which stated that single administration of glibenclamide had no significant effect on CAT activity but glibenclamide in combination with honey up-regulated CAT activity in diabetic treated animal [23].

The previous study has shown the relationship between sexual hormonal and oxidative stress but the information on the effects of gestational diabetes on maternal sexual hormonal profiles is still scanty [27, 28]. In this study, the FSH, PRL, PROG, and E2 were significantly increased in glibenclamide and insulin groups when compared with the diabetic group but the LH was significantly decreased in glibenclamide group when compared with diabetic and insulin group. An increased level of FSH and PROG was in line with the findings of Jihan, Noon and Omer [28].

\section{Conclusion}

Based on our observations in this study, glibenclamide is as effective as insulin in reducing maternal blood glucose level in gestational diabetes mellitus, in improving fetal liver cytoarchitecture, in reducing oxidative stress (as measured by levels of antioxidant enzymes and MDA), and in ameliorating altered maternal sexual hormones with no or little negative effects. Therefore, the glibenclamide could be an optional drug to be used in the treatment of gestational diabetes mellitus.

\section{Acknowledgements}

The authors acknowledge IBRO-Writing Paper Workshop (2017) committees for their mentorship and hands-on practical for paper writing.

\section{Statement of Conflict of Interest}

Nothing to declare/no conflict of interest.

\section{References}

[1] Aguwa CN. Diabetes mellitus In: Therapeutic basis of climate pharmacy in the tropics. Optimal publishers, Enugu, Nigeria 1996; 1-453.

[2] Kalra B, Gupta Y, Singla R, Kalra S. Use of oral anti-diabetic agents in pregnancy: A pragmatic approach. North Am J Med Sci 2015; (7): 6-12.

[3] Kuwata C, Saeki N, Honda K, Matsuoka T, Tsuchiya Y, Shimomura K. Effects of Maternal Hypoglycemia on Fetal Eye and Skeleton Development in Rats. Reproductive Toxicology 2017;

http://dx.doi.org/10.1016/j.reprotox.2017.05.009.

[4] Bennett WL, Robinson KA, Saldenha IJ, Wilson LM, Nilcholson WK. High priority research needs for gestational diabetes mellitus. J. womens health 2012; (1): 925-32.

[5] Nwanjo HU, Nwokoro EA. Antidiabetic and biochemical effects of aqueous extract of vernonia amygdalina leaf in normoglycaemic and diabetic rats. J Inno Life Sci 2004; (7): 6-10.

[6] World Health Organisation (WHO), Facts Sheets to the Ministerial Technical Working Group (TWG) on the United Nations High Level meeting on Non-communicable Diseases ( NCDs) WHO Representative for Nigeria ( Dr. David Okello). Abuja July 2011. 
[7] Ogunmodede OS, Oseni SO, Akinbisoye AA, Adenmosun OO. Dracaena arborea leaf extract: A phytotherapeutic option for ameliorating oxidative stress-mediated endocrine and testicular disorders in alloxan-induced diabetic rats. Journal of Coastal Life Medicine 2015; 3 (10): 809-814.

[8] Harrison SA, Brunt EM, Goodman ZD, Di BIsceglie AM. Diabetic hepatosclerosis: diabetic microangiopathy of the liver. Archives of pathology and laboratory Medicine 2006; (16): 271-274.

[9] Bell, D. S \& Allbright, E. The multifaceted association of hepatobiliary disease and diabetes. Endocrine Practice 2007 13, 284-289.

[10] Gbotolorun SC, Oremosu AA, Osinubi AAA, Noronha CC, Coker HAB, Silva BO. Ameliorative effect of vitamin E on the deleterious effect of Amodiaquine hydrochloride (AQ. $\mathrm{HCL}$ ) on the reproductive function of the adult cyclic Sprague-Dawley (S-D) rats. Biology and Medicine 2012; 4 (3): 141-146.

[11] Byer SL, Wiles MV, Dun SL, Taft RA. Mouse Estrous cycle identification tool and images. Plos ONE 2012; 7 (4): 13601371.

[12] Szkudelski T. The mechansim of alloxan and streptozotocin action in B cells of the rats' pancreas Physiol. Res 2001; (50): 536-546.

[13] Ding, S, Shen Z, Chen Y, Sun S, Liu Q, Xie M. Pioglitazone can ameliorate insulin resistance in low-dose streptozotocin and high sucrose-fat diet induced obese rats Acta Pharmacologian Sinica 2015., 26 (5), 575-580.

[14] Guariguata L, Linnen Kamp U, Beagley J, Whiting DR, Cho NH. Global estimates of the prevalence of hyperglyceamic in pregnancy. Diabetes Res Clin. Pract 2014; (103): 176-85.

[15] Bharti Kalra, YashGupta, Rajir Singla and Sanjay. Use of Oral anti-diabetic agents in pregnancy: A pragmatic Approval. N Am. J. Med Sci 2015., 7 (1): 6-12. PMC 4325398.

[16] Levri KM, Slaymaker E, Last A. Metformin treatment for over-weight and obese adults: a system review. Ann Fam Med 2005; (3) 457-461.

[17] Montserrat Balsells, Apoloria Garcia-Pati, Marta Rogue, ignasi G, Rosa Corloy. Glibenclamide, metformin and insulin for the treatment of gestational diabetes. A systematic review and meta-analysis. BMJ 2015; 350-355 doi. http//dx.doi.org.

[18] Ogunmodede OS, Oseni SO, Oyekan JO, Lawal SK, Adeoye
OA. In vivo Studies on the Phytotherapeutic and Fertility Effects of Dracaena Arborea Extract in Alloxaninduced Type 1 Diabetic Male Rats Br J Med Med Res. 2016; 11 (5): 1-18.

[19] Rehman Khan. weight gain \& insulin therapy Br. J. diabetes vasc Dis 2004; (4): 264-7.

[20] Gary Schenier M. S. Insulin and weight gain, BD diabetes (BD. com). Diabetes learning center 2006. 1-3.

[21] Cotzee EJ, Jackson WPU. Oral hypoglycaemics in the first trimester and fetal outcomes. S. Afr. med J 1980; (61): 795802.

[22] Sripriya L, Vijayalakshmi M. altered lipid profile and antioxidant status of gestational Diabetes mellitus International Journal of Research in Pharmaceutical and Nano Sciences 2013. 2 (5): 622- 627 ISSN: 2319 - 9563.

[23] Omotayo Owomofoyon Erejuwa, Siti Amrah Sulaiman, Mohd Suhaimi Abdul Wahab, Kuttulebbai Nainamohammed, et al., Antioxidant Protective Effect of Glibenclamide and Metformin in Combination with Honey in Pancreas of Streptozotocin-Induced Diabetic Rats Int. J. Mol. Sci 2010; (11) 2056-2066; ISSN 1422-0067 doi:10.3390/ijms11052056.

[24] Elliot BD, Langer O, Schenker S, Johnson RF. insignificant transfer of glyburide coours across the human placenta. Am. J. Obster. Gynecol 1991; (165) 807-812.

[25] Kinalski M, Sledziewski A, Telejko B, Kowalska I, Kretowski A, Zarzycki W, Kinalska I. Lipid peroxidation, antioxidant defence and acid - base stats in cord blood at birth: the influence of diabetes. Horm Metab Res 2001; (33): 227-231.

[26] Tony Rydberg, Anders Jonsson, Michael Roder, Arne Melander, hypoglycemic activity of glyburide (glibenclamide) metabolites in humans. Diabetes Care 1994; 17 (9): 1-6.

[27] Sugino N, Nakamura T, Ishimatsu M, Kato H. Changes in activities of superoxide dismutase and lipid peroxide in corpus luteum during pregnancy in rats. J Reprod Fertil 1993; 97: 347-351.

[28] Selim F, Wael A, and Keith E. Jackson. Diabetes-Induced Reactive Oxygen Species. Mechanism of Their Generation and Role in Renal Injury. Journal of Diabetes Research. 2017, 1-30. https://doi.org/10.1155/2017/8379327.

[29] Jihan Mohammed Mohieldin., Noon Babiker, Omer Mohamed Abdallah. Effect of type 2 diabetes mellitus on sudanese male fertility. sch. j. app. med. Sci 2016; 4 (6e): 2216-2223, ISSN 2320-669. 